Title: Physical activity as leisure: The meaning of physical activity for the health and well-being of adolescent women

Published Brooks, F. and J. Magnusson, Physical activity as leisure: The meaning of physical activity for the health and well-being of adolescent women. Health Care For Women International: Special Edition, Health and Leisure., 2007. 28(1): p. 69-87.

\author{
Author for Correspondence \\ Dr Fiona Brooks \\ Head of Adolescent and Child Health Research \\ CRIPACC, \\ The University of Hertfordshire, \\ Hatfield, AL10 9AB, UK \\ email f.m.brooks@herts.ac.uk \\ Phone +44 (0)1707 285994 \\ Fax +44 (0)1707 285995
}


Physical activity as leisure: The meaning of physical activity for the health and well-being of adolescent women

\begin{abstract}
Globally low participation in physical activity by adolescent young women is represented as a major health concern. While the barriers to activity for this group are well documented, little is known about the views and experiences of non-athlete, but active, young women. In order to gain an understanding of young women's lived experiences of the relationship between physical activity as leisure and health, data were collected through focus groups. Active non-athlete young women in the UK attached significant meaning to physical activity as a space for leisure, and actively used it to enhance their health and well-being.
\end{abstract}

Key Words: Adolescent girls and physical activity, physical activity as leisure, health and well-being 


\section{Physical activity as leisure: The meaning of physical activity for the health and}

\section{well-being of adolescent women}

\section{Introduction}

Unhealthy lifestyles based on sedentary leisure activities have been represented as the defining characteristic of current youth cultures (BMA, 2003; Royal College of Physicians, 2004; Smith \& Green, 2005; WHO, 2002). The most common argument is that young people's lack of participation in sport and physical activity is directly equated with a dramatic rise in childhood obesity (Fruhbeck, 2000). Among girls and young women ${ }_{2}$ adolescence often marks a dramatic decrease in physical activity levels as the activities that girls participated in during childhood are abandoned (Mulvihill, Rivers, \& Aggleton, 2000; Rees et al., 2001; Williams, Bedward, \& Woodhouse, 2000). For example, in the $\mathrm{UK}_{2}$ recent data shows that among $13-15$ year olds, $30-40 \%$ of boys and $50-60 \%$ of girls do not undertake the recommended one hour of moderate physical activity per day to maintain physical health (Department of Health, 2002; Health Education Authority, 1998). Further studies in the USA have found the figure for girls inactivity to be as high as 75\% among school years 10-12 (Pate et al., 2002). However, most of these studies have focused their attention on participation in organized sports and have tended to ignore the informal physical activities in which young people may take part. Leisure spaces devoted to sport and physical activity can be significant areas through which gender identities are explored, established and reinforced for adolescents (McRobbie, 1978; Wearing, Wearing, \& Kelly, 1994), and as such how girls and young women occupy such leisure spaces are worthy of detailed consideration. In relation to physical activity, feminist work has been particularly important for shifting concern away from girls and young women as problem non-participants who do not wish to develop 
athletic bodies, to providing a critique of the gendered character of sport provision (Cockburn \& Clarke, 2002; Flintoff \& Scraton, 2001; Garrett, 2004).

Aspects of physical education (PE) provision in school and community leisure provision have been shown to reinforce reduced participation in physical activity for adolescent girls through less access and choice, hostile responses from boys and the dominance of a competitive discourse within schools that does not support the development of young women's physical skills (Vilhjalmsson \& Thorlindsson, 1998). Moreover, girls and young women have been found in general to particularly dislike aspects of traditional team sports in which individual performance failure is negatively sanctioned by the whole team (Brooks \& Magnusson, 2006; Flintoff \& Scraton, 2001). In terms of public recreations spaces similar constraints have also been found to exist with differential opportunities and provision for young women and men, gendered family expectations and the influence of stereotypical gender roles, all serving as barriers to adolescent girls participation in leisure spaces devoted to physical activity (Culp, 1998). These may result in young women having little choice but to, either 'opt' for sedentary leisure pursuits or to develop strategies to reduce their visibility when they do participate in the public leisure spaces of the swimming pool, the playing field and the gym $(\mathrm{K}$. James, 2000, 2002). Structural inequalities in access to physical activity and sports provision for women have in the past also resulted in young women having fewer physically active role models, thereby reinforcing their exclusion from physical activity as leisure (Garcia et al., 1998).

While the barriers to activity for young women are increasingly well documented, little is known about the views and experiences of active, young women who readily 
occupy leisure spaces devoted to physical activity. The purpose of this paper is to explore the meaning of physical activity as leisure for young women and to provide an account of $\underline{\text { their perspective on the relationship of such leisure pursuits to their health and well- }}$ being.

\section{Literature Review}

Adolescents have been found to identify much of what is important to them as being located predominantly within their leisure pursuits (Kelly \& Freysinger, 1999). Previously studies of women's leisure have tended to highlight the value and meaning for girls and young women of social interaction with peers in the passive spaces of the bedroom and school toilets, while boys play sports on the field, young women have a 'laugh with the girls,' (Green, Hebron, \& Woodward, 1990; Griffin, Hobson, McIntosh, \& McCabe, 1982; Scraton, 1994). While this body of work has highlighted the autonomy, pleasure and support offered by social interaction between women (Green, Hebron, \& Woodward, 1990; McRobbie, 1978), more recently, work has explored how the 'bedroom' as dominant leisure space can be less of a positive choice by adolescent girls and instead represent the only venue where girls feel sufficiently safe that they can be themselves (K. James, 2001). Henderson (1996) has argued for sometime that there is a need to move away from 'a one size fits all' in understanding women's relationship to leisure pursuits and explore all the potential dimensions of the relationship for women. The body of work on adolescent girls' recreation, raises a number of further questions concerning the value and meaning of participation in physical activity for young women, notably how young women might be engaging in public recreation spaces? 
The views and experiences of active adolescent women are important to consider, firstly, because active lifestyles have been found to have an array of positive health and social benefits for young people, including positive impacts on emotional well being (Aarnio, Kujala, \& Kaprio, 1997; Garrett, 2004; Kirkcaldy, Shephard, \& Siefen, 2002; Steptoe \& Butler, 1996; WHO, 2002). Secondly, there is a need to consider the impact of more recent social, cultural and generational influences that may have created a change in the desire and ability of young women to engage in physically active leisure pursuits.

The emergence in late modernity of modified forms of femininity may allow for the possibility of greater physical agency among young women and an increased ability to challenge masculine domination of public recreation spaces. Reflected in popular culture through 'girl power' and media representations of young women who display physical prowess as for example, in the TV series 'Buffy' (Bellafante, 1997), the 'can do girl' stands for a new identity based on the possibilities of choice, individualism and self invention (Harris, 2004; Walkerdine, Lucey, \& Melody, 2001). Sports advertising for some time has reflected this emergent sense of personal power among women (MacCurdy, 1994) a trend that can be more recently seen in the Nike campaign 'tell me I'm not an athlete' depicting ordinary women as powerfully active (Nike, 2006). Overall the potential existence of the 'can do girl' appears to merit a re-consideration of the relationship of more recent generations of young women to physical activity.

Current generations of young women also have potential access to a wider range of physical activity leisure pursuits, as evidenced by the growth in youth participation in new sporting forms such as snow boarding, rock climbing and martial arts. These activities, along with an increased variety of dance forms available to young women 
(Wearing, Wearing, \& Kelly, 1994) have characteristics that tend to allow for individual skill development, as well as being more co-operative in nature (Thorpe, 2005) and are favoured by those who dropped out of team-based sports provision upon leaving school (Tomlinson, Ravenscroft, Wheaton, \& Gilchrist, 2005). Characteristics which appear to be attractive to a growing number of girls and young women who are taking up extreme or alternative forms of sport (Thorpe, 2005).

Over the last decade it has also been suggested that participation in physical activity could be an empowering experience for women in general and may provide a site of resistance to dominant subordinating gendered ideologies and discourses (Henderson, 1990, 1996; McDermott, 1996, 2000). Physical activity as leisure may increase women's confidence to challenge gendered stereotypes and restrictions (Gilroy 1989). Physical activity in this analysis could function to allow for the development of a more pro-active sense of self for girls and adolescent women (Wearing, Wearing, \& Kelly, 1994). Elsewhere we have highlighted how through participation in activities such as dance, girls acquired confident and more self assured physical identities, with resulting positive impacts on their self esteem (Brooks \& Magnusson, 2006). However, it has been suggested that instead of creating empowered bodies, physical activity is more likely to engender conformity with idealised patriarchal notions of female forms (Dworkin \& Messner, 1999). The sense of empowerment attained through increased physical strength may in reality be a double-edged sword for women, as their bodies are no longer congruent with ideologies of conventional femininity and therefore they become socially 'deviant' (Gilroy, 1997). In a study of adolescent girls negotiation of femininity in relation to UK physical education in schools (PE), participation in school sport resulted in 
a 'sizeable femininity deficit' that obliges girls to choose between being physically active and heterosexually desirable (Cockburn \& Clarke, 2002).

However how young women might be experiencing alternative physical activity spaces from the traditional formalized sport opportunities and particularly outside of the school culture of physical education is worthy of further consideration. It may be that informal physical activity leisure spaces may offer a very different subjective experience for young

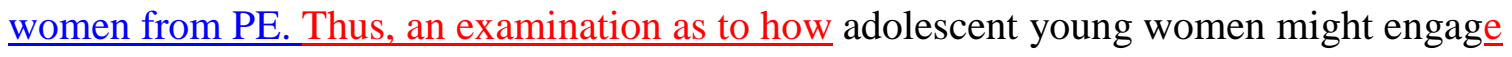
in physical activity during their leisure time and if such activity can serve as a strategy of empowerment, is worthy of examination.

\section{Theoretical framework}

For this study we drew on the body of work collectively known as the "new social studies of childhood' (Christensen \& James, 2000; James, Jenks, \& Prout, 1998).

Underpinning this body of work is the definition of the child as an active social actor, who has the ability to make sense of their own life. Moreover, the child can employ the meanings they construct to negotiate with and resist the surrounding adult world; including resisting being moulded towards the 'end goal of adult society,' (Christensen \& James, 2000; James, Jenks, \& Prout, 1998; Toren, 1993). Defining the child as an active social actor and the attendant rejection of them as 'cultural dupes' (Mayall, 1998) allows for an understanding of young people's engagement in leisure activities as being shaped by different interpretations and priorities to those of the adults in their lives (James, Jenks, \& Prout, 1998; Toren, 1993). Consequently, it becomes possible to perceive sedentary leisure pursuits such as; 'chatting in the bedroom' as practices of health 
maintenance, if they reinforce friendship networks and prevent exposure as a physically poor performer. Participation in physical activity can also be understood not just as a means to reduce childhood obesity, but as an adolescent leisure activity that potentially has a wide range of both positive and negative impacts for adolescent health.

The conceptualisation within the new social studies of childhood ' of the child in time', as an individual and as a member of a specific generation (James, Jenks, \& Prout, 1998), offers a means to understand young people responses to leisure spaces that may be highly fluid within and across specific generations. Adolescent identities cannot be assumed to be fixed as either active or inactive, but instead, are open to change as the young person negotiates and responds to alterations in activity provision and their social environment (Flintoff \& Scraton, 2001).

Overall, the recognition that children hold their own concepts about physical activity as leisure, and the health benefits of activity that may stand in polar opposition to adult conceptualisations, creates a research agenda where the child's perspective on their leisure experiences necessarily becomes the central analytic task.

\section{$\underline{\text { Purpose }}$}

In this paper we report the results of a qualitative study that set out to examine the $\underline{\text { views and experiences of non-athlete young women aged (13-16 years) who were self }}$ identified as being committed to at least one form of physical activity. We were concerned with adolescents for whom physical activity occupies their leisure time, but who were not training or seeking to attain 'sporting excellence' in traditional, professional competitive terms, that is what we term non-athletes. By focussing on nonathlete adolescents we sought to add to the nuanced understanding of the lived 
experiences of 'unremarkable girls'(Cockburn \& Clarke, 2002), thereby addressing the experiences of young women who may be typically representative of active UK girls (Cockburn \& Clarke, 2002).

The objectives of this paper were to address two specific dimensions of the lived experiences of young women:

- To explore how active adolescent women relate to and experience physical activity as a leisure pursuit, including the forms of activity and the key characteristics of physical activity that were defined by the young women as $\underline{\text { leisure. }}$

- To examine adolescent women's experiences and perceptions in terms of the relationship between physical activity and health and well being.

\section{Method}

The findings presented here are part of a larger study looking at the promotion of physical activity to young people both male and female, through UK family practice/health centres. Elsewhere we have explored the responses of both young men and young women to physical education provision (Brooks \& Magnusson, 2006). This paper presents a coherent analysis of the young women's accounts and is drawn from the qualitative part of the larger study, whereby two chorts of teenagers participated in focus groups.

\section{Focus groups}

_ To gain an in-depth understanding of the meaning of physical activity in young people's lives, a series of focus groups were conducted with 36 young women who self 
identified as being physically active, but who did not identify themselves as current or potential athletes. None of the young women were pursuing dedicated or intensive training designed to achieve high-level competitive excellence or identified their future careers as sporting performers. All the adolescents reported that they regularly and voluntarily engaged in at least one physical activity during their leisure time, these included activities such running, cycling, swimming or trampolining, team sports such as netball clubs, newer sporting forms such as skateboarding or martial arts and activities such as dance. Some of the activities were formally structured and organised through school or clubs, others were informal self-organised activities.

The focus groups were selected from two settings. One cohort were recruited through a postal (mail) invitation to take part, sent to 13-16 year old young people who were on the list of patients of a medium size general medical practice $(n=429)$ in a small city in England. The city has an even deprivation profile, with all wards (electoral and administrative division of which there are 10,661 in the UK, average population 5500) below the median score of deprivation for England. However pockets of poor health exist within the area served by the medical practice, with the main area having a poor health domain of +0.27 (a score $>0.10$ is considered to constitute a poor health area).

The second cohort of focus groups were undertaken through a local secondary school, where the young people $\underline{\text { in }}$ one school year group (grade) (UK year group 9, age range 14-15) were given an invitation letter by their teacher. In both cases participation was entirely voluntarily and took place outside of scheduled school hours. The school was located in an electoral sub-ward of significant deprivation and poor health status. The index of multiple deprivation (IMD) rated the ward with a high score of 28.06 , (IMD =1 
most deprived and 865 least deprived) and with a poor health domain score of +0.33 .

The ethnic composition of both areas was primarily white in origin.

In the first cohort, two focus groups (11 participants) with young women were completed.

In the second cohort, five mixed gender focus groups were undertaken, consisting of 31 young people in total (25 of which were girls).

Sample. In the school based sample, the composition and number of the focusgroups in the school was decided by the young people. This enabled them to control who they were interviewed with and to ensure that the research process minimised the potential of the research intensifying any problematic relationships (such as bullying) within the school year group. Smaller groups or paired interviews were also offered. The recruitment process resulted in mixed gender established friendship groups, with a majority of young women in each focus group. By giving control over the composition of the focus-groups to the young people, we were also able to include young people who would only agree to be interviewed about this topic in their established friendship groups, for example a group of committed dancers ( 7 girls, 1 boy).

All focus group participants were aged between 14 and 16 years. There was no difference found between the views expressed in the mixed gender focus groups and the single sex ones. This may be due in part to the dominance of young women in the mixed groups and that they were interviewed in self -selecting friendship groups.

Data Collection. The focus-group interviews with the young people sought to elicit experiences of physical activity and group discussion relating to, the meaning and value of physical activity for them, and what helped or hindered them from undertaking physical activity. Questions explored current activity levels and forms of participation, 
how they had changed over time, the relationship between participation in school physical education and leisure pursuits, the perceived benefits and drawbacks to participation in physical activity. Participants were also asked about the impact of physical activity as a leisure pursuit on their perceptions of self, their physical identity, and peer relationships. Strategies to aid the discussion included, exploring responses to magazine images of 'active' young people engaging in physical activity and sport from UK teen magazines (Cosmogirl!, Bliss, and Just 17) and an 'ice breaker' whereby participants at the start of the focus group wrote down the meaning to them of terms such as physical activity and sport and the facilitators used this as a starting point to the discussion.

The focus groups were facilitated by two female researchers, (the authors). Focus group interviews as a methodological tool offered a number of advantages for addressing the core aims and objectives of the study. Foremost, they ensured that priority was given to uncovering each respondent's categorisation and language. In addition as a form of group interview, the focus groups enabled not just an analysis of individual responses, but also consideration of the interactional features of the data (Kitzinger, 1995). All the interviews were taped and transcribed. Thematic coding was employed and themes were generated both inductively from the raw data and deductively employing the theoretical framework drawn from the new social studies of childhood (Boyatizis, 1998). Both of the authors coded all of the transcripts separately, the data were categorised into initial and higher codes and were repeatedly searched for disconfirming cases as part of the coding refinement process. 


\section{Ethical Considerations}

Formal consent was gained from all the participants and parents were made aware of the study. Local ethical committee approval was granted for the study. All participants have been anonymised and pseudonyms used in the presentation of the data.

In addition to young people in the school sample having control over which groups they participated, ethical considerations also structured the conduct of the focus groups. Young people were made aware that they could leave at any time and that they were not obliged to answer any of the questions and a phrase was given to all respondents that they could use if they wished to leave. The researchers also stressed that this was a nonjudgemental process and that there were no right or wrong answers to any of the questions. Refreshments were also provided. The young people were also asked for their comments on the conduct of the focus-group and how they felt about the questioning strategy. All participants were given a voucher as a thank-you for participating. 


\section{Findings}

For the adolescent women taking part in the focus groups, physical activity as a leisure pursuit had multi-dimensional meanings and value. Physical activity as we shall explore, was both a strategy to find individual expression and space, but also an area for enjoyable engagement with peers. The focus groups also enabled additional insight into young women's perceptions on the nature of the relationship between physical activity and emotional well-being.

Physical Activity as Leisure: Not competing but being challenged

Young women engaged in a range of physical activities that occupied their leisure time outside of school hours, including team sports, informal self-organised activities such as cycling, new sporting forms such as martial arts and activities such as dance. In the interviews the majority introduced themselves as possessing strong personal preferences both for and against particular activities as can be seen in the words of Palvi, $\underline{\text { Caron and Sue: }}$

Okay I'm Palvi, I like sport and I do athletics and horse-riding and stuff at school and just go for a jog at the weekends.

My name is Caron and I enjoy sport in general but I really enjoy cycling and running.

I'm Sue and I'm 15. I like tennis, swimming, athletics, most sports really apart from I don't like football (soccer) and hockey that much.

Previous research has found that inactive girls and young women dislike the traditional 'girls' team based sports of hockey and netball due to the dominance of a sporting 


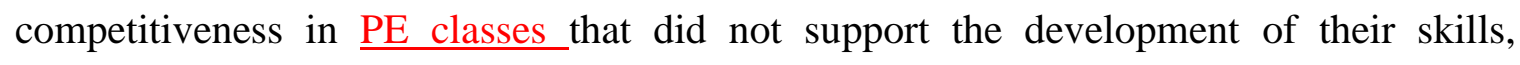
coupled with a 'fear' of letting the team down if their personal performance was weak (Flintoff \& Scraton, 2001; Garrett, 2004). In the focus groups active young women also tended to express aversion to the competitiveness in traditionally organised team based sports. In the same way that inactive young women have been found to reject such activities because they dislike the pressure created by having to attain sporting excellence and success, active young women also find the prominence in certain sports on taking responsibility for the team winning to be problematic, with a potentially negative impact on their sense of well-being. These sentiments can be seen in Myang's comments:

Yeah, sometimes the competitive sports, like I play netball, but if things really build up in your mind, like if you're losing, nobody likes losing and it really builds up and you really hate yourself for it, like I'm the goalkeeper and it's say letting the goals in, it's really annoying and everyone's tutting as well so sometimes like yeah, when it's non-competitive it clears your mind.

In the view of the young women we interviewed attaining high level physical performance was not a factor that influenced their participation in an activity or sport. However traditional competitive sports such as team sports, or activities such as tennis, were leisure sites for the young women if they provided opportunities for fun, relaxation and social support, as Keria explained:

On Friday nights we go and play in my club and that's something social, that's why I like tennis the most, I think because I can do that as well because I find 
sport more fun if I'm not doing it in a competitive environment. I don't like being competitive, it's more for relaxation and just something to do (laughs).

Rather than seeking a primary site of body performance or physical attainment, the young women appeared to be more interested in participating in activities they felt enhanced their emotional well-being.

The dislike of traditionally organised, competitive sports did not mean that the young women wished to avoid being physically challenged. Instead many stated in the focus groups that one of the most positive aspects of participating in physical activity was the sense of doing an activity that was demanding, in terms of the physical challenge it presented. As Rachel explained "Anything that takes you out of your comfort zone...it makes you use something that's not what you're used to using, if you work hard".._Many of the young women stated that they were engaging in sports or activates that could be described as adventurous, physically demanding and in some instances requiring displays of aggression, such as rugby, karate skiing/snow boarding. The enjoyment of physical exertion was equated in the majority of accounts with positive implications for health and wellbeing, specifically feeling less tired and having increasing energy levels both physical and psychological were mentioned by many of the young women as a benefit for participating in challenging activities. As Serena said, "It probably refreshes me because if I've just had a day at school and I'm tired and then I go swimming or play a sport, that sort of wakes me up a bit to sty awake longer."

Physical Activity as Leisure: The 'fun' factor

An additional factor that seemed to cause the young women to reject certain activities and express preferences for others was that they were applying a 'fun' rating to 
the different contexts in which the activities occurred. In particular settings that encouraged and valued their commitment to participate, rather than athletic excellence were felt to provide a more enjoyable and accessible context. The majority of interviewees expressed a clear distinction between school based physical education and activity outside of school as the following discussion illustrates:

Interviewer: So where do you do your sports?

Holly: Yeah well I do, do it in school but I prefer it outside of school.

Interviewer: Why do you prefer outside school

Ruth: Well I have lessons and it's just a friendly club and it has all my friends there and it's just more enjoyable outside of school, I think.

Angela: In my school as soon as they pick the team you're not allowed to go to the school clubs or anything because it is only for the team...(in the club) they will say oh she is committed and she's come to the club that many weeks, they'll let you still play as part of the team. So that is quite good. You never feel like you can't go because your not good enough. 
Those activities that provided individuals with control over how they could be engaged with were seen as being most enjoyable. Control was defined in the young women's accounts as being, able to relax and 'not worry' about feeling pressured to attain high standards of performance 'excellence', but also provided an opportunity to develop their skills._In this framework both cycling or walking on your own and taking part in competitive sports such as tennis or netball, could for example be defined as enjoyable leisure pursuits, if the young women felt they had control over how they engaged with the activity:

\section{Interviewer: What aspect is most important to you?}

Karen: At school that can be quite competitive at times like swimming because you have to be like racing each other, you have to be the best, but if you do it for leisure its more, you know...

Jane: Yeah I gave up swimming, like I used to go to swimming classes but then I stopped because after a while I didn't feel I was getting any more out of it, because we were just like doing the same thing again and again and again every week. So I just left and now I go swimming by myself.

In terms of the respondents' views on the link to their health and well-being the attachment of significance to contextual features of leisure activities allows for an explanation of why some would feel walking at the weekend was intrinsically healthy, $\underline{\text { that is, }}$. because it could be challenging, relaxing and enjoyable, while routine activities such as walking to school could be defined as being of little value to their health as it failed to be challenging, failed to raise their heartbeat and was simply not fun. As Jackie 
explained, "No I don't see walking to school as, (physical activity) that wouldn't do anything for you, wouldn't even raise you heartbeat."

\section{Physical Activity as Solo Leisure Space}

In previous studies concerned with young women's leisure the positive impacts of the collective, social aspects of adolescent girls' leisure has been stressed (Green, Hebron, \& Woodward, 1990; Griffin, Hobson, McIntosh, \& McCabe, 1982; Scraton, 1994). For the respondents in this study physical activity was also valued because it constituted a private solo recreational space. Kathy James (2001) found that adolescent girls valued their bedroom as a space they controlled and where they could spend time alone. Physical activity was used by some young women in our study in a similar way, to achieve a personal recreational space away from other demands, such as parental control and even their friends. In addition physical activity such as, running or cycling, was explicitly perceived by the young women as enhancing their emotional health and well being, including serving as a way of dealing with severe emotional distress such as bereavement. Angela spoke about her recent experiences of losing one of her grandparents:

Recently my granddad died and the night that I found out about it, well actually I was there, but when I came back, my first day back at school, it was either a choice of sitting at home and thinking about it or going out and I decided to go out and run, you know do some exercise.

The active young women in the focus groups consciously used solo exercise to promote psychological health. It could be used as a "pick-me-up" after a tiring day or as a way of managing the routine stress of school and social life. In this way exercise became a leisure space where young women as individuals were able find a means to achieve 
emotional balance. Claire explained, "I think also it's to clear your mind and stuff because sometimes like when I go out cycling in the evening, I feel really agitated or whatever before but then I just forget about it." For some of the young women solo physical activity dominated their leisure, because key forms of public recreational activity spaces such as gyms or exercise classes were felt to be too intimidating. Primarily these public spaces were perceived to be the province of active adults, and consequently spaces where the adolescents' competence and body might be highly visible and open to censure. Diane said:

My mum goes to the gym and she'll ask if I want to come and I just say 'no' and go for a jog somewhere else. I don't really like going to gyms and that is because in case you went on a machine and didn't know how to work it and you just feel really embarrassed and that every-one was looking at you.

Overall, for some engaging in solo activities was a reflection of feeling excluded and marginal in more public spaces. In the main, however solo physical activity was valued by the young women because it provided a positive leisure space that they could use for maintaining their emotional health and well-being.

\section{Physical Activity as a Venue for Social Leisure Time}

As well as being a way of increasing overall well-being, physical activity was also seen as an opportunity for socialising with existing friends and family and also for extending their friendship networks beyond the realm of school. For some exercising with family was valued for the way that it provided a space whereby they could communicate easily with other family members particularly their parents. Mary said, "Like walking, that's why I like walking, at least then I can talk to my parents and my grandparents." Often, physical activity also served to provide a venue for meeting other adolescents (both male and female) who they would not socialise with outside of the physical activity context. 


\section{Louise spoke of joining a sport club and explained that, "Since I joined a couple of years}

ago I've made a load of new friends who I never see during the week, except that night I go to the club" (talking about male and female friends). Likewise, Helen spoke about her relationship with her friends, she said, "I have this whole other group of girls, I see because we all play together and we have all been friends for years." Participation in sport as a chosen leisure activity was in this context a means for young women to widen friendship networks into their local communities and create new supportive social networks based on shared interests. As Holly and Ruth explained:

Holly: It's a good way to make friends, as well if you go to a club outside school. Interviewer: how does it help make new friends?

Ruth: Well, you just meet new people.

Doing activities together with friends also appeared to give these young women an opportunity to do sports without the competitive element of feeling that they had to do better than their friends. Not being in competition with your friends was discussed as an important aspect of their continued participation in sports and physical activity. Moreover having a sport/activity that was different from your school friends gave the young women a valued individuality, as the following discussion illustrates:

Holly: I don't think it's to be better, I prefer that I do it so that I'm with my friends and have fun with them rather than like trying to beat them.

Amy: All my friends are good at different sports, one of my friends is brilliant at rugby and she coaches young people as well and my other fired is really good at cross-country and athletics and then I do swimming and my other fired does 
dancing as well but she does it at a higher standard than I do and so we've all got different sports and I think that's good because there's no competitiveness, we just get on with our own sports.

The young women were not averse to participating in sports that have traditionally been seen as competitive sports. However they tended to state that they highly valued being able participate in activities in a relaxed atmosphere together with their friends, irrespective of the form of sporting activity, as Ruth explained:

My name is Ruth, I am 14 years old and I'm in Year 9 at school. I like walking, I'm not very keen on competitive sports, basically because I'm not very good at them and yes I like walking and I like running. I like ones where you can like talk while you're dong them so then it's kind of sociable as well as kind of like exercise.

Engaging in activities that their peers valued were significant influences on the forms of activity that young women engaged in, activities that were seen as babyish or 'too girlie' were particularly likely to be viewed negatively. In some cases negative responses from peers partly accounted for activities being dropped as Serena recounted:

I stopped doing cheer-leading because I just thought it was so pointless and every-one was like, 'oh you do cheer-leading?' (negative sarcastic voice) and I was like okay. You know the carnival, I had to do it and I got really embarrassed and I didn't go after that.

Activities that were valued by peers and that provided opportunities to gain social standing were likely to encourage continued or increased participation, for example the dance group felt that opportunities to perform socially in highly visible ways in front of 
their peers were extremely enjoyable and rewarding experiences as is illustrated in the following discussion:

Kirsty: I've only recently started dance, I used to just dance in my bedroom (laughs).

Paul: You dance at clubs too

Kirsty: I do now, I love clubbing and dancing

Kim: Yeah you can't get us off the dance floor

Kirsty: It was Kim's birthday the other week and she had a party and we made and played the Moulin Rouge song that we're dancing to and we done our dance at her party.

Kim: Yeah I do love to dance. 


\section{Discussion}

This study reported on non-athlete adolescent women's views and experiences of participating in physical activity as part of their leisure time. Engaging in activities that they felt provided opportunities for enjoyment and relaxation was of central importance to young women. Control and choice over the activity, was something the young women felt was also essential to their enjoyment of physical activity as leisure. However from the perspective of the young women an activity that was perceived as offering opportunities for relaxation could also physically challenging and therefore 'energising'.

Work on adolescent girls' identity formation and leisure has highlighted the value for girls of the bedroom as a private individual space where they can feel free to be themselves (K. James, 2001). Just as activities associated with time spent in their bedrooms (listening to music, reading magazines) have been identified as important to identity formation the accounts from the active young women in this study highlighted how physical activity can also represent a significant personal solo leisure space. Young women particularly appeared to value solo physical activity as a strategy for managing stress and for the maintenance of their emotional well-being.

In previous studies (Green, Hebron, \& Woodward, 1990), the importance of socialising with friends has been portrayed as the dominant focus of young women 's leisure, in this study young women used physical activity leisure opportunities as a social space for interacting with peers and family members. For these physically active young women ${ }_{2}$ the significance of 'having a laugh with the girls', was still important to them, but they had relocated this activity out from the bedroom and the school toilet into a wider range of active leisure spaces. The young women in our study were readily 
occupying activity spaces that provided them with opportunities to engage positively with peers and gain emotional benefits from physical activity without having to conform to masculine normative expectations of competitive success.Adolescent women actively engaged with spaces such as tennis and netball clubs that in the young women's terms facilitated participation rather than competitive sporting objectives and they rejected those venues such as school based clubs that still conformed to them.

Although the young women were engaging in activities that located them within public recreation spaces, conversely there was also little evidence that they were openly 'can do girls' (Harris, 2004; Walkerdine, Lucey, \& Melody, 2001) who fully occupied the range of leisure spaces available for recreational physical activity. Previous research has highlighted how young women adopt strategies that seek to minimalise their visibility in public sporting leisure spaces (K. James, 2000). The active adolescent young women in this study modified their choice of activity and location in order to manage tensions caused by overt physical visibility. Our study further identified that this feeling of 'being on display' for the young women was often associated not simply with the types of clothes that were worn during certain activities, but also to the context of the delivery of such activities. Hence, the young women sought public leisure spaces for physical activity that offered a means to participate without heavy emphasis on competitive success and also enabled them to extend their opportunities for creating positive friendship networks.

The strategies for physical activity engagement enacted by the young women in our study also represent positive resistance to masculine modes of sporting engagement such as prioritising competitive performance and attainment. These young women had moved 
their leisure out from domestic spaces, while successfully maintaining and reinforcing the forms of leisure that they found most rewarding such as quality social interaction with peers. They could not be said to be directly challenging gendered stereotypes and restrictions through increased physical prowess (Gilroy 1989). Instead the active young women seemed to employ physical activity leisure sites to enhance their sense of wellbeing and social confidence, thereby contributing to the potential emergence of a more pro-active sense of self (Wearing, Wearing and Kelly 1994).

The young women were very clear about how they perceived physical activity to be related to their general health and well-being. The new social studies of childhood asserts that young people hold their own conceptualisations and priorities about health and health maintenance that may diverge significantly from adult conceptualisations (Mayall, 1998). The prevailing adult constructed health promotion agenda stresses the need for young people to increase their physical fitness and thereby attend to the linked obesity agenda. However achieving or maintaining physical health was not a strong feature among the reasons why adolescent women pursued physical activity as leisure. Instead physical activity was more likely to be valued as a means of attaining both emotional well-being and positive social relationships. Adolescence represents a time of high emotional stress for young people as they face multiple transitions encompassing the physical, psychological, educational and social aspects of their lives. In terms of emotional well-being, physical activity was a leisure space that enabled such stressful life events to be managed and supportive peer relationships established, by providing both a space for supportive social interactions and a place for personal solo emotional management. This emphasis by young women on the emotional and social benefits 
suggests that health promotion initiatives that simplistically stress the physical health benefits of activity for young women may actually have little impact, or may even have a detrimental effect on participation in physical activity.

\section{Conclusions}

In this paper we explored the relationship between physical activity as a leisure pursuit and the health and well-being of a previously under researched group, that of active adolescent women. Central to leisure research is the concept of leisure as a life

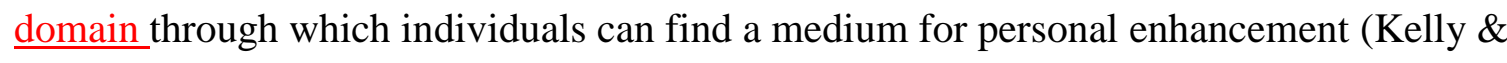
Freysinger, 1999). Feminist work on physical activity and leisure has suggested that sport participation could either be a means of empowerment for women (Wearing, Wearing, \& Kelly, 1994) or vehicle that engenders conformity to patriarchal notions of the female form (Dworkin \& Messner, 1999). Central to the argument advanced in this paper is that for active adolescent women physical activity can be a significant empowering experience with respect to the amelioration of the stressful aspects of their lives. Overall physical activity for young women can be a leisure space that they perceive has profoundly positive implications for their health and well-being 


\section{Acknowledgements}

We would like to thank all the young people for their time and involvement in the study; we hope we have been true to their experiences. Many thanks also go to Wendy Wills, Hilary Thomas and Helena Wythe for commenting on drafts of the paper and to the LEAP steering group for their support throughout the study. The study was funded by the Hertfordshire Primary Care Research Network (HertNet). 


\section{References}

Aarnio, M., Kujala, U. M., \& Kaprio, J. (1997). Associations of health-related behaviors, school type and health status to physical activity patterns in 16 year old boys and girls. Scandinavian Journal of Social Medicine, 25(3), 156-167.

Bellafante, G. (1997, 5 May). Bewitching Teen Heroines. Time, pp. 82-85.

BMA. (2003). Adolescent Health. London: British Medical Association Board of Science and Education.

Boyatizis, R. (1998). Transforming qualitative information: Thematic analysis and code development. Thousand Oaks, CA: Sage.

Brooks, F., \& Magnusson, J. (2006). Taking part counts: Adolescents experiences of the transition from inactivity to active participation in school based physical education. Health Education Research, Available on line May 2006.

Christensen, P., \& James, A. (Eds.). (2000). Research with Children: Perspectives and Practices. London: Falmer Press.

Cockburn, C., \& Clarke, G. (2002). Everybody's looking at you!: Girls negotiating the feminity deficit they incur in physical education. Women's Studies International Forum, 25(6), 651-665.

Culp, R. (1998). Adolescent girls and outdoor recreation: A case study examining constraints and effective programming. Journal of Leisure Research, 30(3), 356379.

Department of Health. (2002). Health survey for England 2002: The health of children and young people. London: Department of Health. 
Dworkin, S., \& Messner, M. (1999). Just Do...What? In M. Marx Ferree, J. Lorber \& B. Hess (Eds.), Revisioning Gender (pp. 341-361). Thousand Oaks, CA: Sage.

Flintoff, A., \& Scraton, S. (2001). Stepping into active leisure? Young women's perceptions of active lifestyles and their experiences of school physical education. Sport, Education and Society, 6(1), 5-21.

Fruhbeck, G. (2000). Childhood obesity: time for action, not complacency. Definitions are unclear, but effective interventions exist. British Medical Journal 320 (7231)(Feb 5), 328-329.

Garrett, R. (2004). Negotiating a physical identity: Girls, bodies and physical education. Sport, Education and Society, 9(2), 223-237.

Gilroy, S. (1997). Working on the Body: Links Between Physical Activity and Social Power. In G. Clarke \& B. Humberstone (Eds.), Researching women and sport (pp. 96-112). London: MacMillan Press.

Green, E., Hebron, S., \& Woodward, D. (1990). Women's leisure, what leisure. Basingstoke: Macmillan.

Griffin, C., Hobson, D., McIntosh, S., \& McCabe, T. (1982). Women and leisure. In J. Hargreaves (Ed.), Sport Culture and Ideology. London: Routledge and Kegan Paul.

Harris, A. (2004). Future girl: young women in the twenty-first century. London: Routledge.

Health Education Authority. (1998). Young and active? Young people and healthenhancing physical activity - evidence and implications. London: Health Education Authority. 
Henderson, K. (1990). The Meaning of Leisure for Women: An Integrative Review of the Research. Journal of Leisure Research, 22(3), 228-243.

Henderson, K. (1996). One size doesn't fit all: The meanings of women's leisure. Journal of Lesiure Research, 28(3), 139-154.

Hill, R., Williams, J., Britton, J., \& Tattersfield. (1991). Can morbidity associated with untreated asthma in primary school children be reduced?: a controlled intervention study. British Medical Journal, 303(Nov 9), 1169-1174.

James, Jenks, C., \& Prout, A. (1998). Theorizing childhood. Cambridge: Polity.

James, K. (2000). 'You can feel them looking at you': The experiences of adolescent girls at swimming pools. Journal of Leisure Research, 32(2), 262-280.

James, K. (2001). I just gotta have my own space!: The bedroom as a leisure site for adolescent girls. Journal of Leisure Research, 33(1), 71-90.

James, K. (2002). Adolescent girls' leisure: A conceptual framework highlighting factors that can affect girls' recreational choices. Annals of leisure research, 5(1), 14-26.

Kelly, J. R., \& Freysinger, V. (1999). 21st Century Leisure: Current Issues. New York: Benjamin-Cumming Publishing Company.

Kirkcaldy, B. D., Shephard, R. J., \& Siefen, R. G. (2002). The relationship between physical activity and self-image and problem behaviour among adolescents. Soc Psychiatr Epidemiol, 37, 544-550.

Kitzinger, J. (1995). Qualitative research: Introducing focus groups. British Medical Journal, 311(29 July), 299-302. 
MacCurdy, M. (1994). The Four Women of the apocalypse: Polarized Feminine Images In Magazine Advertisements. In L. Manca \& A. Manca (Eds.), Gender and Utopia in Everything: A Article Reader (pp. 31-48). Lisle, IL: Procopian Press.

Mayall, B. (1998). Towards a sociology of child health. Sociology of Health and Illness, 20(3), 269-288.

McDermott, L. (1996). Towards a Feminist Understanding of Physiciality Within The Context of Women's Physically Active and Sporting Lives. Sociology of Sport Journal, 17(4), 331-363.

McDermott, L. (2000). A Qualitative Assessment of the Significance of Body Perception To Women's Physical Activities Experiences: Revisiting Discussions of Physicalities. Sociology of Sport Journal, 17(4), 331-363.

McRobbie, A. (1978). Working class girls and the culture of femininity. In A. McRobbie (Ed.), Women take issue. London: Hutchinson.

Mulvihill, C., Rivers, K., \& Aggleton, P. (2000). Views of young people towards physical activity: determinants and barriers to involvement. Health Education, 100(5), 190-199.

Nike. (2006). nikewomen.com. Retrieved 27 February 2006

Pate, R., Freedson, P., Sallis, J., Taylor, W., Sirard, J., Trost, S., et al. (2002). Compliance with Physical Activity Guidelines: Prevalence in a Population of Children and Youth. AEP, 12(5), 303-308.

Rees, R., Harden, A., Shepherd, J., Brunton, G., Oliver, S., \& Oakley, A. (2001). Young people and physical activity: A systematic review of research on barriers and facilitators. London: EPPI-Centre, University of London. 
Royal College of Physicians. (2004). Storing up problems: the medical case for a slimmer nation. London: Royal College of Paediatrics and Child health and the Faculty of Public Health Medicine.

Scraton, S. (1994). Boys muscle in where angels fear to tread - girls sub-cultures and physical activities In C. Critcher, P. Bramham \& A. Tomlinson (Eds.), Sociology of Leisure. London: Taylor and Francis.

Smith, A., \& Green, K. (2005). The place of sport and physical activity in young people's lives and its implications for health: some sociological comments. Journal of Youth Studies, 8(2), 241-253.

Steptoe, A., \& Butler, N. (1996). Sports participation and emotional wellbeing in adolescents. The Lancet, 29(347), 1789-1792.

Thorpe, H. (2005). Jibbing the gender order: females in the snowboarding culture. Sport in Society, 8(1), 76-100.

Tomlinson, A., Ravenscroft, N., Wheaton, B., \& Gilchrist, P. (2005). Lifestyle sports and national sprot policy: an agenda for research: report to Sport England. London: Sport England.

Toren, C. (1993). Making History: The significance of childhood cognition for a comparative anthropology of mind. Man, 28(3), 461-478.

Vilhjalmsson, R., \& Thorlindsson, T. (1998). Factors related to physical activity: a study of adolescents. Social Science and Medicine, 47(5), 665-675.

Walkerdine, V., Lucey, H., \& Melody, J. (2001). Growing up girl: psychosocial explorations of gender and class. Basingstoke: Palgrave. 
Wearing, B., Wearing, B., \& Kelly, K. (1994). Adolescent women, identity and smoking: leisure experience as resistance. Sociology of Health and Illness, 16(5).

WHO. (2002). World Health Report 2002: Reducing risk -promoting healthy life. Geneva: World Health Organization.

Williams, A., Bedward, J., \& Woodhouse, J. (2000). An inclusive curriculum? The experience of adolescent girls. European Journal of Physical Education, 5(1), 418. 